\title{
The Application of Silver to Decontaminate Dental Unit Waterlines-a Systematic Review
}

\author{
Feiruo Hong ${ }^{1,2} \cdot$ Piaopiao Chen ${ }^{1,2} \cdot{\text { Xuefen } \mathrm{Yu}^{1} \text { (D) } \cdot \text { Qianming Chen }}^{1}$
}

Received: 23 November 2021 / Accepted: 3 January 2022 / Published online: 8 January 2022

(c) The Author(s), under exclusive licence to Springer Science+Business Media, LLC, part of Springer Nature 2022

\begin{abstract}
The contamination of dental unit waterlines (DUWLs) is a major health concern since it can pose cross-infection risks among dental professionals and their patients. Silver is one of the widely used metals in medical fields due to its superior antimicrobial properties. Silver-based agents have been commercially available for the decontamination of dental unit water currently. This systematic review aims to examine the evidence supporting efficacy and safety of application of silver to decontaminate DUWLs. We performed a search of the peer-review literature of studies in six electronic databases using corresponding search terms. Eligibility was restricted to English-language studies exploring the application of silver to decontaminate dental unit water, e.g., silver-based disinfectants and silver-coated dental waterlines tubing. The search identified 148 articles, and 9 articles that met the criteria were synthesized with qualitative narrative analyses. We observed good evidence of antimicrobial efficacy of silver with hydrogen peroxide on diverse microorganism present in DUWLs. Furthermore, there is insufficient evidence on the application of silver nanoparticles (AgNPs) as an efficient material to control the biofilms in DUWLs. Post-treatment data of either the bactericidal and bacteriostatic effects of silver or AgNPs, especially the actual clinical efficacy of long-term application, are scarce. More high-quality research is needed to resolve the gap on the optimal dosage and treatment options required to control bacterial and biofilm in DUWLs with silver-containing materials.
\end{abstract}

Keywords Dental unit $\cdot$ Silver $\cdot$ Water quality $\cdot$ Biofilms $\cdot$ Nanoparticles $\cdot$ Disinfection

$\begin{array}{ll}\text { Abbreviations } \\ \text { DUWLs } & \text { Dental unit waterlines } \\ \text { DCU } & \text { Dental chair unit } \\ \text { CFU/mL } & \text { Colony forming unit/milliliter } \\ \mathrm{HPC} & \text { Heterotrophic plate count } \\ \mathrm{Ag} & \text { Silver } \\ \mathrm{AgNPs} & \text { Silver nanoparticles } \\ \mathrm{NMS} & \text { Nanometer silver } \\ \mathrm{H}_{2} \mathrm{O}_{2} & \text { Hydrogen peroxide } \\ \mathrm{FLA} & \text { Free-living amoebae } \\ \text { QS } & \text { Quorum sensing }\end{array}$

Xuefen Yu

yuxf@zju.edu.cn

1 Stomatology Hospital, School of Stomatology, Zhejiang University School of Medicine, Zhejiang Provincial Clinical Research Center for Oral Diseases, Key Laboratory of Oral Biomedical Research of Zhejiang Province, Cancer Center of Zhejiang University, Hangzhou 310000, Zhejiang, China

2 School of Medicine, Zhejiang University, Hangzhou 310000, Zhejiang, China

\section{Introduction}

The dental unit waterlines (DUWLs) are responsible for the delivery of therapeutic water, which are essential for dental treatment. Waterline interconnected tubes are commonly made by several opaque, narrow-borne (mostly $2 \sim 3 \mathrm{~mm}$ inner diameter) soft plastics [1]. Due to their small inner diameter and composition, waterlines provide a favorable environment for the growth and reproduction of microorganisms [2], enabling the formation of highly structured biofilms on the surface of internal tubing [3]. Biofilm is a cluster of microbial communities attached to a surface and/ or to each other embedded in a self-produced extracellular matrix [4]. In comparison to planktonic bacteria, biofilm is more adaptable to the natural environment, which means it is often much more resistant to adverse conditions such as antimicrobial agents and antibiotics [5]. Even with the newly installed dental chair unit (DCU), the total number of microorganisms in water can be greater than $2 \times 10^{5}$ colony-forming units $(\mathrm{CFU}) / \mathrm{mL}$ in 5 days [6]. However, regarding the standard for dental water quality, the guideline established by the US Centers for Disease Control and Prevention 
(CDC) recommends that the heterotrophic plate count (HPC) of output water should be less than $500 \mathrm{CFU} / \mathrm{mL}$ [7]. The European Commission (EC) is adopting the drinking water standard as a reference, which sets a limit of $100 \mathrm{CFU} / \mathrm{mL}$ on the heterotrophic bacterial load [8].

Biofilm is the most important source of water pollution in DUWLs [9]. Many studies over the last 60 years have demonstrated that a wide array of bacteria, fungi, and protozoa had been isolated from these biofilms including both environmental and opportunistic pathogens, predominantly gram-negative bacteria [8]. These microorganisms pose a potential hazard to the health of patients and medical staff. The fragments of biofilm in DUWLs, which are transferred into the mouth of the patient, may lead to acute and chronic infections on different levels [10] or maybe even serious systemic infection. A part of biofilms, which are transformed into the portion of aerosols around DCU, are prone to be inhaled by dental office staff and patients. Allergenic bacteria in aerosols can induce asthma, rhinitis, allergic alveolitis, organic dust poisoning syndrome, or other more dangerous diseases [11]. Moreover, the particle size distribution of aerosols may facilitate SARS-CoV-2 cross-infection [12]. Although there is no direct evidence that the contamination of DUWLs will cause the occurrence of diseases currently, a case of an 82-year-old patient without basic diseases who died of Legionella pneumophila infection after receiving dental treatment was later confirmed that the cause of death was highly related to the contamination of dental unit water [13]. We are currently facing the unprecedented challenge of the COVID-19 pandemic, which has led to greater concern about this risk. Because of the alarming situation, effective and evidence-based practical approaches for controlling the biofilms of DUWLs are urgently needed.

Silver-based disinfection agent is one of the commercially available chemical products for decontamination of the DUWLs. Silver (Ag) had been used as antibacterial agents because of its potent antibacterial properties since ancient Greece [14]. Silver nanoparticle (AgNP), as a microbicide, is one of the widely used nanoparticles in the medical field, such as wound dressings, urinary catheters, and dental materials $[15,16]$. Besides the antibacterial ability, several studies have demonstrated the superior antiviral activity of AgNPs against human pathogenic viruses such as human immunodeficiency virus (HIV) and hepatitis B virus [17]. Moreover, it has been recently reported that AgNPs can effectively inhibit SARS-CoV-2 by disrupting viral integrity [18]. In addition to employing as disinfectant agents, silver has been proposed as a component of coatings applied to the luminal surface of waterline tubing in inhibiting the biofilm formation. Some manufacturers have utilized the technology to produce dental unit waterlines that adopt silver coating, such as manufactured by A-Dec ${ }^{\circledR}$ (A-Dec Inc., Newberg, OR, USA).
There is no doubt that the determination of antibacterial mechanism is of great significance to the application of silver, and there are several mechanisms have been described currently, such as extracellular binding or precipitation to bacterial cell walls and membranes as well as binding to cellular proteins, deoxyribonucleic acid (DNA), and electron donor groups [19].

Moreover, the exploration of the antimicrobial mechanism of AgNPs is still in its infancy. A portion of studies considered that the antimicrobial activity of AgNPs contributed to their nanoforms, rather than silver ions released [20]. Some authors suggested that the release of silver ions was responsible for the antimicrobial action of AgNPs, whereas the particle-specific activity of AgNPs was paltry [21]. An interesting review figured out that the activity of AgNPs with a size below $10 \mathrm{~nm}$ was mainly by nanoparticle itself; while at larger sizes, the mechanism occurred predominantly through the releasing of silver ions [22]. Zhang et al. [23] summarized the antimicrobial mechanism of AgNPs in the aquatic environment. Due to the high surface area-to-volume ratio, AgNPs are prone to oxidative reactions when being exposed to water. The released silver ions destroy the protein structure of bacteria in water, afterward, the production of reactive oxygen species (ROS) leading to oxidative stress enhances their antimicrobial effect. Various pathways are generally considered to involve the antimicrobial action of AgNPs, including increasing permeability of cell membranes, inhibiting protease activity, and blocking DNA replication and transcription [24].

The "quorum sensing (QS)" of bacteria is a communication mechanism for bacterial cell-to-cell connection. Bacteria regulate gene expression by perceiving the variation of cell concentrations in the surrounding environment through their own secreted signaling molecules, which increases their virulence against adverse circumstances [25]. Strains of bacteria in water with the QS system have been continuously isolated and purified, and some of them have been demonstrated to take advantage of QS to aggravate the formation of biofilms, such as Bacillus cereus, Vibrio cholera, and common bacteria in the aquatic environment [26]. It was also discovered that the DUWLs isolates, such as Pseudomonas aeruginosa, Achromo bacter xylosoxidans and Achromobacter spp., can affect the ability of biofilm-forming through QS system [27]. Considering that the presence of bacterial QS plays the role in the development of biofilm to a certain extent, blocking the bacterial QS is proposed as a feasible means to control the occurrence of biofilm formation [28]. Emerging evidence suggests that AgNPs may also have antiQS properties [29]. AgNPs can significantly down-regulate QS-regulated genes, especially the genes encoding virulence factor secretion [30]. A recent study demonstrated that AgNPs adopted the means of inhibiting LasI/RhlI synthase to block the biosynthesis of signaling molecules [31]. These 
results indicated that AgNPs may possess anti-QS characteristics, which enables them to interrupt signaling paths within biofilms. However, there are few studies on the mechanism of QS directly relating to DUWLs.

To date, there have been several original studies of the antibacterial efficiency of various silver type disinfectants applied in dental water $[32,33]$. However, to our knowledge, we are not aware of a systematic review that is trying to answer the question, "How effective is silver against microbes in dental unit waterlines?." On this basis, the aim of this systematic review is thus to examine the evidence supporting efficacy of clinical application and antimicrobial potential of silver to decontaminate DUWLs.

\section{Materials and Methods}

\section{Eligibility Criteria}

Eligibility was restricted to English-language studies exploring the application of silver to decontaminate dental unit water, e.g., silver/AgNPs-based disinfectants or silver-coated dental waterlines tubing. Exclusion criteria included reviews and investigations that had no quantitative data available. Studies that focus on the effectiveness of other disinfecting strategies, such as automatic disinfection system applying silver/AgNPsbased disinfectants, were excluded from this review.

\section{Search Strategy}

The research was conducted to evaluate relevant studies by using six online databases, including PubMed, Scopus, Web of Science, EMBASE, ProQuest, and Ovid. The key terms used for database searches are listed in Table 1. The lists of references from identified articles were also searched. Articles were restricted to publication between 1 January 2010 and 30 September 2020.

\section{Study Selection and Quality Assessment}

After completing the search, all citations were imported into EndNote to remove duplicates. Subsequently, two researchers independently assessed the title, abstract, and full paper of each article to determine eligibility for inclusion in the systematic review. All divergence between the two reviewers was resolved by consensus. The methodological quality of the study was assessed by using the risk of bias in nonrandomized studies of interventions (ROBINS-I) tool [34]. The following seven domains were investigated: (1) bias due to confounding, (2) bias in selection of participants into the study, (3) bias in classification of interventions for all outcomes, (4) bias due to departures from intended interventions for all outcomes, (5) bias due to missing data for all outcomes, (6) bias in measurement of outcomes, and (7) bias in selection of the reported result. Any discrepancies were discussed until the reviewers reach an agreement and the paper documented as low, moderate, serious, critical risk, and no information.

\section{Data Extraction}

The data were extracted from each article by two reviewers and organized by using a PICO (population, intervention, comparison, outcome) framework. Population data included the sample size, service time of the dental units, water supply modes, and the type of targeted microorganisms. Intervention data included the type and characteristic of silver, such as the brand of disinfectant, the concentration of silver/AgNPs, and the applying way. Comparison data included the detail of the comparison group (e.g., dosage and frequency of use). Outcome data included the efficiency of antimicrobial (e.g., anti-bacterium, antimycotic, antivirus, and anti-biofilms) and the adverse effect relating to these decontamination methods. The country where the study was conducted was also obtained as population variables.

\section{Results}

After a literature search of six electronic databases, 148 records were identified. Through other sources, we included three additional records. There left 71 records for further screening after removing duplicates. There were 55 records removed by title/abstract screening because of the inconsistent study aim, leaving 16 studies for full-text review. At the end of the process, we included 9 eligible publications in the systematic review. The reasons for exclusion in the step of full-text screening are shown in Fig. 1.
Table 1 Key terms used for databases searches

\begin{tabular}{ll}
\hline Search No & Search terms \\
\hline 1 & silver OR silver nanoparticle* OR Ag OR AgNP* OR nanosilver OR nano* silver \\
2 & dental unit OR dental water OR dental unit waterline* OR DUWL* OR dental \\
& tube* OR dental unit pipe* \\
3 & disinfect* OR decontaminat* OR agent OR coat* \\
4 & 1 AND 2 AND 3 \\
\hline
\end{tabular}


Fig. 1 Preferred Reporting Items for Systematic reviews and Meta-Analyses (PRISMA) 2009 Flow chart illustrating the study selection

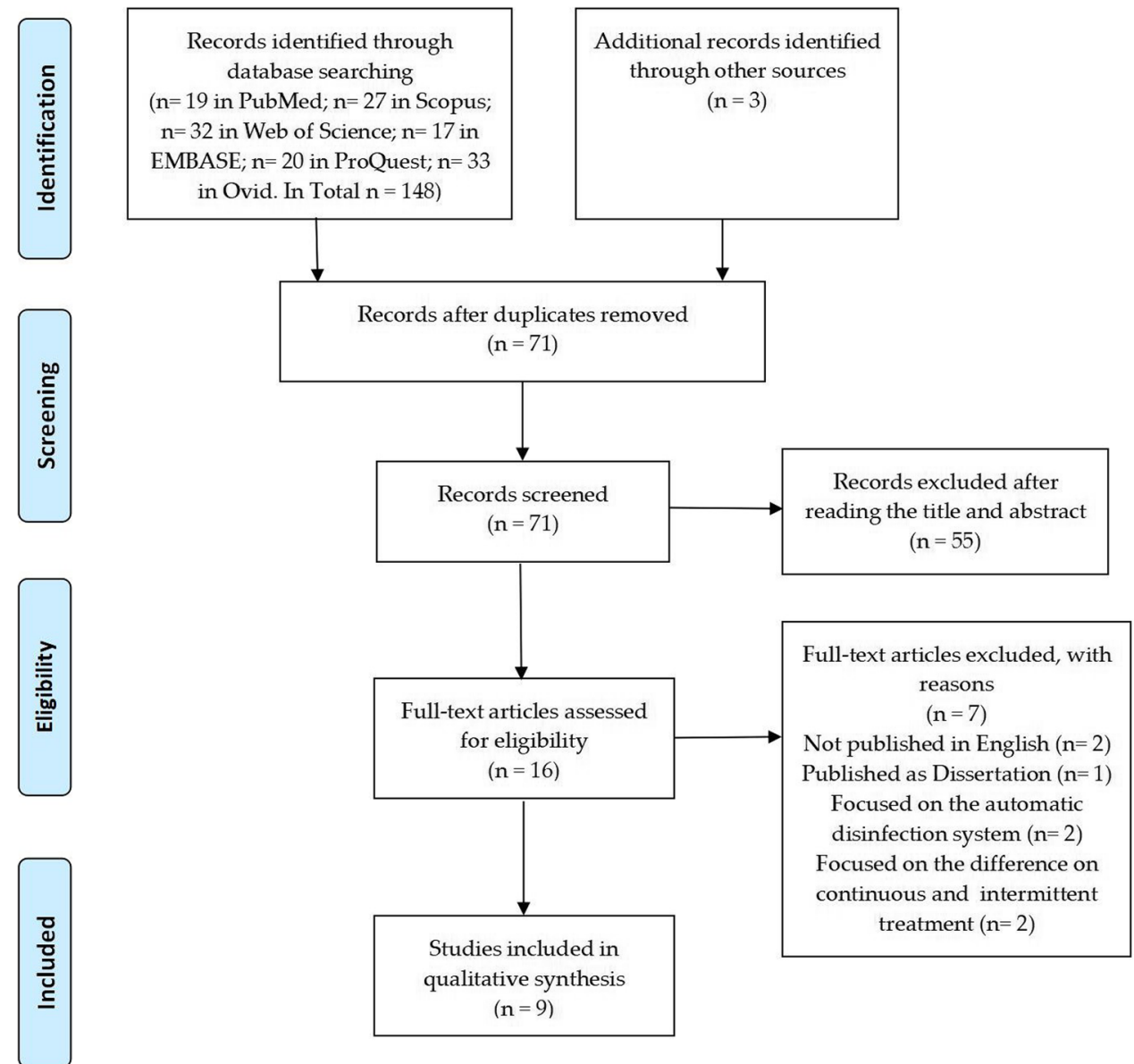

Among these articles, one paper aims to investigate the bacteriostatic effect of AgNPs on biofilm in DUWLs [35], while the purposes of other eight papers are to evaluate the efficacy of silver-based disinfectants (e.g., hydrogen peroxide/colloidal silver) or to compare the effectiveness of various commercial DUWLs disinfectants [3, 33, 36-41]. However, there was no article focusing on silver-coated dental waterlines tubing in dental water treatment. Only one publication that aims to develop a heterogeneous biofilm model for DUWLs mentioned that the proprietary silver coating applied to the commercial waterline failed to resist biofilm formation [42]. Therefore, we were unable to include relevant literature. The main characteristics and the reported results of including studies that examining the antimicrobial effect of disinfectants in dental water are shown in Tables 2 and 3 .

\section{Silver $\left(\mathrm{Ag}^{+}\right)$Compounds Agent}

\section{Silver with Hydrogen Peroxide $\left(\mathrm{H}_{2} \mathrm{O}_{2}\right)$}

Among the included studies, there have been six publications focusing on disinfectant products that contain hydrogen peroxide and silver. The application of silver in DUWLs predominantly works in the form of disinfectant agents acting in synergy with $\mathrm{H}_{2} \mathrm{O}_{2}$.

Özalp et al. [36] investigated reduction in the colonization and growth of heterotrophic bacteria in DUWLs by using $\mathrm{H}_{2} \mathrm{O}_{2} /$ colloidal silver $(83 \mu \mathrm{g} / \mathrm{mL})$ as a disinfectant. The treatment groups were disinfected continuously within 20 weeks, and shock doses were applied every 4 weeks. Through the results of time when significant differences in median reduction in HPC, the authors considered that this disinfection was effective in improving the output water quality. Moreover, the electron microscopic analysis proved that continuous treatment with $\mathrm{H}_{2} \mathrm{O}_{2}$ /colloidal silver was able to remove the biofilm attached to the inner surfaces of the DUWL. Petti et al. [37] tested the disinfectant activity of $\mathrm{H}_{2} \mathrm{O}_{2}$ / silver ions against a series of freshly isolated pathogens, which include Staphylococcus aureus, Enterococcus faecalis, Candida albicans, Pseudomonas aeruginosa, Legionella pneumophila, Mycobacterium chelonae, and non-pathogenic Bacillus clausii spores. These bacterial suspensions were inoculated into the waterlines of pre-sterilized dental turbines, being treated with $\mathrm{H}_{2} \mathrm{O}_{2} / \mathrm{Ag}^{+}$disinfectant $\left(\mathrm{H}_{2} \mathrm{O}_{2} 3 \% \mathrm{v} / \mathrm{v}, \mathrm{Ag}^{+}\right.$ $0.001 \% \mathrm{w} / \mathrm{v}$ ) for $10 \mathrm{~min}$. The mean log load reductions of 







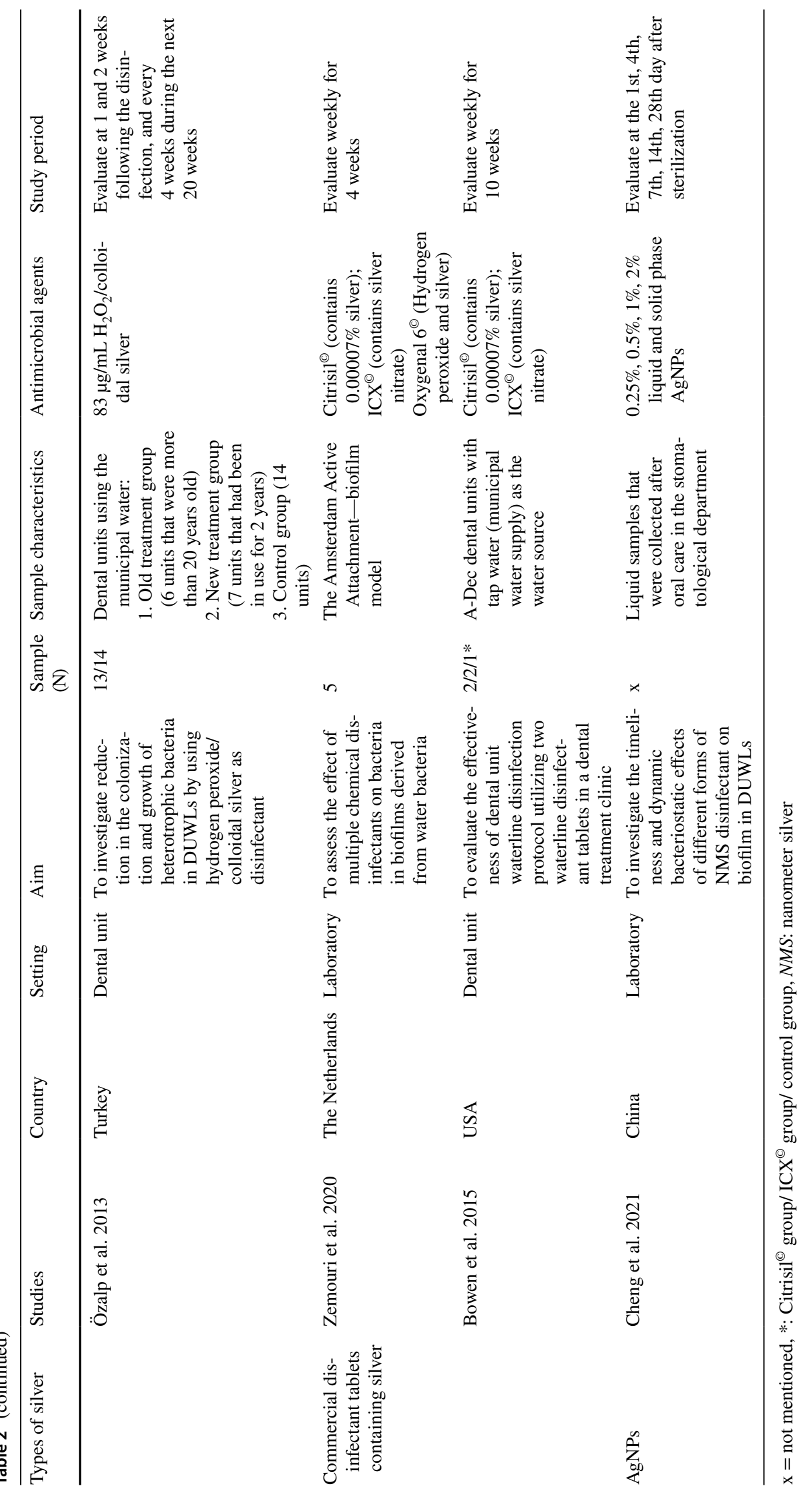




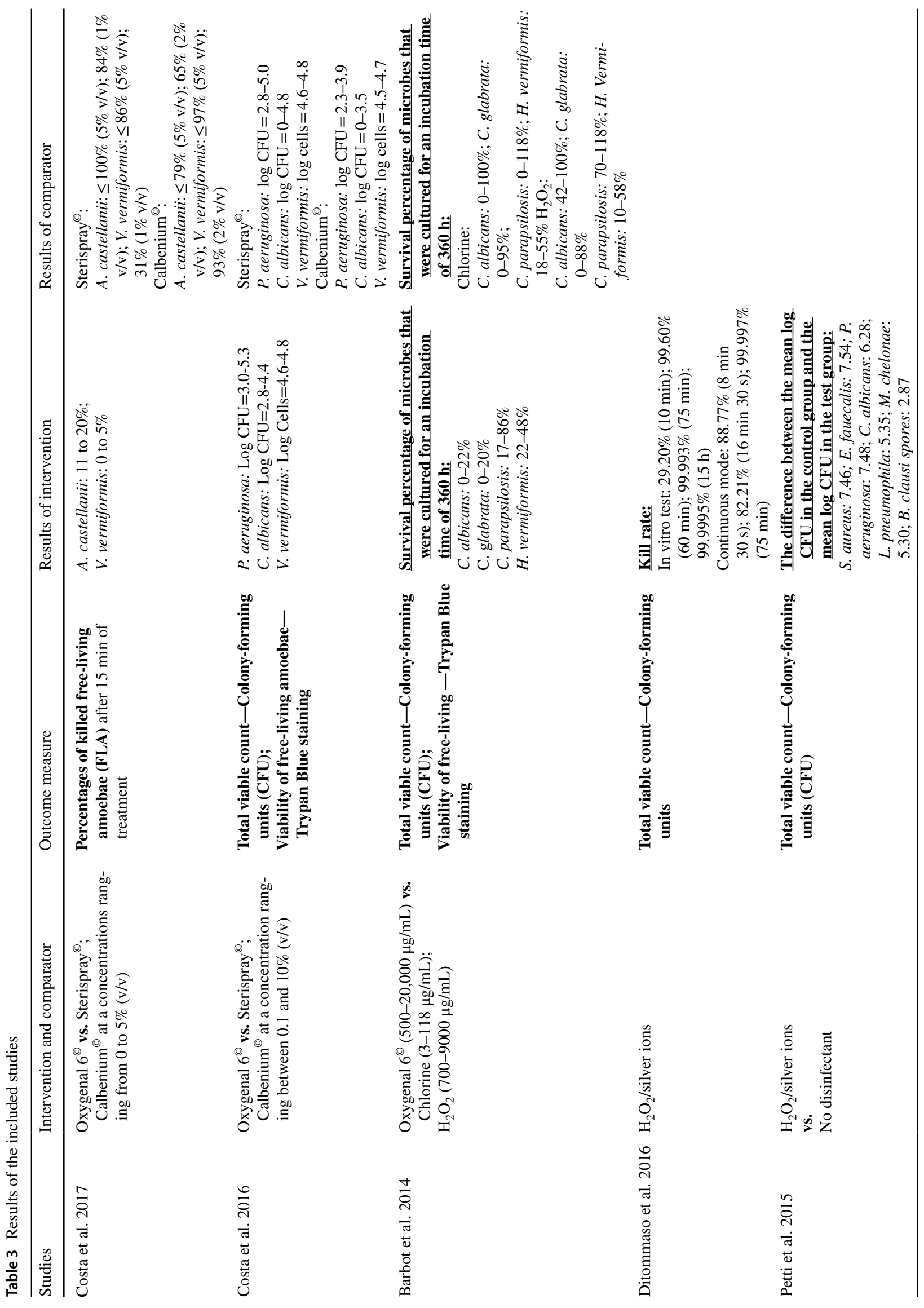




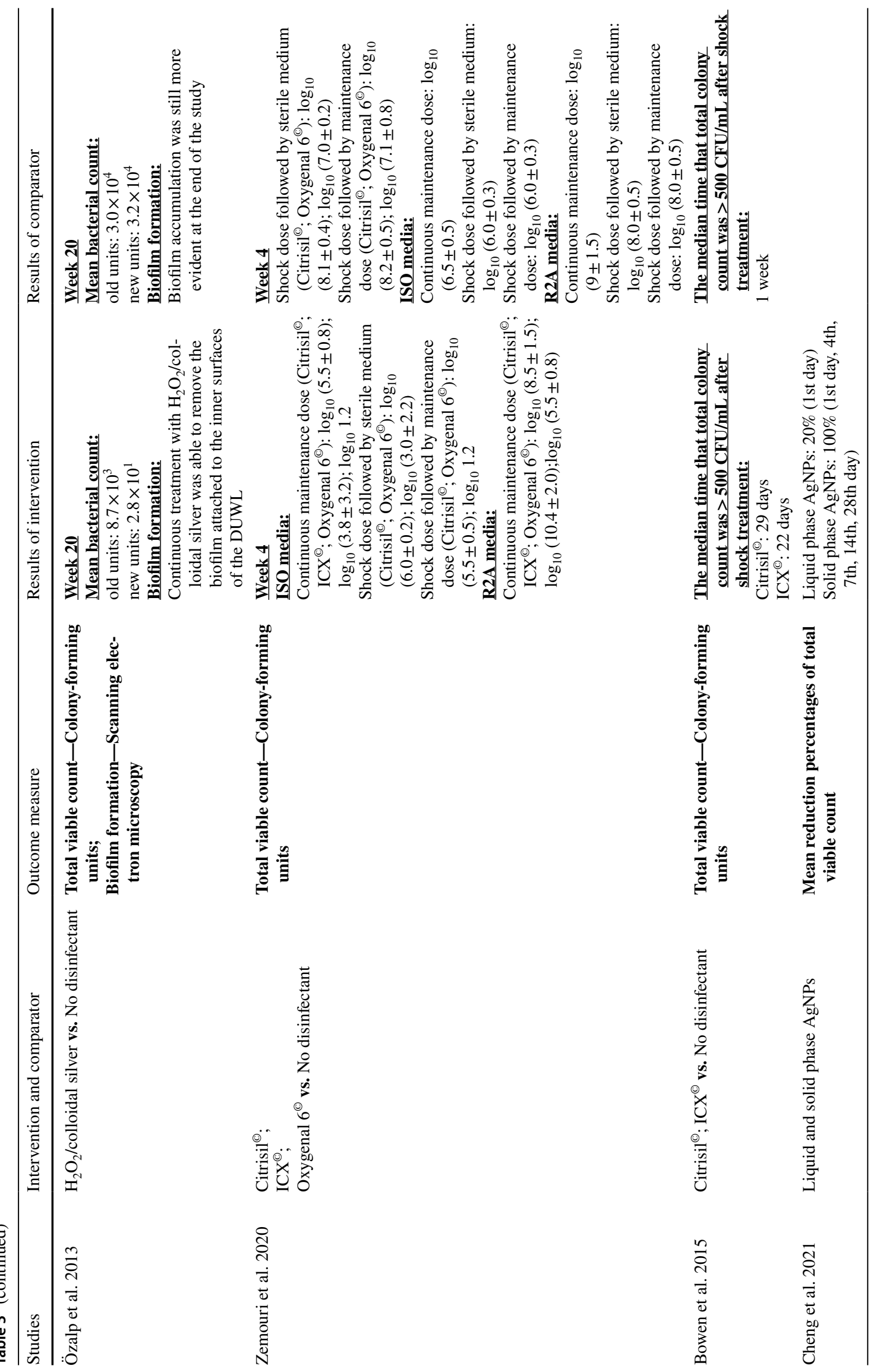


$7.5 \log$ CFU for $S$. aureus, E. faecalis, P. aeruginosa, 6.3 for C. albicans, 5.4 for L. pneumophila, 5.3 for M. chelonae, and 2.9 for B. clausii spores were obtained. Using L. pneumophila serogroup 1 as an indicator organism, the antibacterial capability of the $\mathrm{H}_{2} \mathrm{O}_{2} / \mathrm{Ag}^{+}\left(\mathrm{Ag}^{+} 0.001 \%\right)$ was demonstrated by Ditommaso et al. [33]. With the extension of contact time, the antibacterial efficacy of the disinfectant was also enhanced. Exposure to $\mathrm{H}_{2} \mathrm{O}_{2} / \mathrm{Ag}^{+}$for $75 \mathrm{~min}$ resulted in killing almost all Legionella cells (99.99\%). The remaining three studies involved Oxygenal $6^{\oplus}$ (Kavo, Biberach, Germany), a commercial DUWLs disinfectant product made up of hydrogen peroxide and silver, all carried out by the same research team. Barbot et al. [38] compared the efficacy of three common disinfectants (chlorine, $\mathrm{H}_{2} \mathrm{O}_{2}$, and Oxygenal $6^{\circ}$ ) against three species of Candida (C. albicans, C. glabrata, and C. parapsilosis) and Hartmannella vermiformis in tap water. Oxygenal $6^{\odot}$ was proved to be the most efficacious in preventing the growth of Candida, while chlorine was effective but only at the highest doses tested, and $\mathrm{H}_{2} \mathrm{O}_{2}$ had no significant activity. However, none of these tested disinfectants could eradicate $H$. vermiformis. The authors also pointed out that the difference in efficacy between $\mathrm{H}_{2} \mathrm{O}_{2}$ and Oxygenal $6^{\odot}$ may be due to the presence of other components in Oxygenal $6^{\oplus}$, such as silver ions. Costa et al. [3] evaluated the ability of three commercial disinfectants $\left(\right.$ Calbenium $^{\odot}$, Oxygenal $6^{\odot}$, and Sterispray ${ }^{\odot}$ ) to reduce biofilm formation or to eradicate an already formed biofilm, which contains bacteria ( $P$. aeruginosa), fungi $(C$. albicans), and free-living amoebae (Vermamoeba vermiformis). However, the result demonstrated that the maximum efficiency of Oxygenal $6^{\odot}$ was observed from the concentration of $3 \%$ on $P$. aeruginosa, and it was unable to totally eliminate $C$. albicans in the tested conditions, comparing to other disinfectants. Similar to the previous study, free-living amoebae (FLA) was resistant to all of the disinfectants. A year later, Costa and his colleagues [39] investigated the same three disinfectants at concentrations ranging from 0 to 5\% (v/v) against two FLA species (Acanthamoeba castellanii and $V$. vermiformis). Oxygenal $6^{\odot}$ did not exhibit FLA killing activity, which the killing rate was 11 to $20 \%$ for A. castellanii and 0 to $5 \%$ for $V$. vermiformis, while Sterispray ${ }^{\odot}$ and Calbenium ${ }^{\odot}$ displayed concentration- and species-dependent activities with a maximum eradication rate of $100 \%$ and $86 \%$, and $79 \%$ and $97 \%$ for A. castellani and $V$. vermiformis, respectively.

\section{Commercial Disinfectant Tablets Containing Silver}

Bowen et al. [40] examined the effectiveness of two waterline disinfectant tablets, including ICX $^{\oplus}$ (contains silver nitrate) and $\mathrm{Citrisil}^{\odot}(0.00007 \% \mathrm{Ag})$, on the microbiological quality of dental unit water. The median time for Citrisil ${ }^{\odot}$ and $\mathrm{ICX}^{\odot}$ to increase to more than $500 \mathrm{CFU} / \mathrm{mL}$ in $\mathrm{HPC}$ after shock treatment was 29 days and 22 days, respectively. In addition, 15/20 samples (75\%) taken from the control group using no tablet were $>500 \mathrm{CFU} / \mathrm{mL}$. They reported when comparing $\mathrm{ICX}^{\odot}$ with $\mathrm{Citrisil}^{\odot}$, no significant differences were found, but it was notable that there was a significant difference between the use of either tablet and no tablet. A recent study conducted by Zemouri et al. [41] assessed the effect of several chemical disinfectants, which include $\mathrm{ICX}^{\odot}$, $\mathrm{Citrisil}^{\odot}$, and Oxygenal $6^{\odot}$, on bacteria in a biofilm model. However, the result demonstrated that exposure to $\mathrm{ICX}^{\odot}$ and $\mathrm{Citrisil}^{\odot}{ }^{\odot}$ consistently failed to control the biofilms in the simulated model and Oxygenal $6^{\odot}$ lowered the number of bacteria at continuous maintenance dose.

\section{Silver Nanoparticles (AgNPs)}

Cheng and his coworkers [35] investigated the timeliness and dynamic bacteriostatic effects of two forms of nanometer silver (NMS) disinfectant, including liquid and solid phase, on DUWLs biofilms. They collected bacterial water samples from the stomatological department, being treated with NMS at the concentrations of $0.25 \%, 0.5 \%, 1 \%$, and $2 \%$, respectively. Results revealed that the bacteriostatic rate of liquid phase NMS at all concentrations was only $20 \%$ on the 1st day and massive bacteria re-grew at the days left, while the bacteriostatic rate of solid phase NMS at all concentrations was $100 \%$. Therefore, the authors concluded that NMS had the potential to disinfect microbial contamination in DUWLs, among which solid phase NMS is more bactericidal against bacteria than liquid phase NMS.

\section{Methodological Quality Assessment}

The results of the quality assessment of the studies included in the review can be seen in Fig. 2. In general, we found the following methodological concerns in the aforementioned studies:

In the studies by Cheng et al. [35], Petti et al. [37], and Costa et al. [39], control to prevent other microbial contamination during whole research was not considered, which is an important confounding factor, and altered the results. Some included studies did not mention the sample size, such as studies conducted by Cheng et al. [35], Petti et al. [37], Barbot et al. [38], and Costa et al. [39]. Therefore, the results need further validation.

\section{Discussion}

This systematic review was conducted to understand the application of silver or AgNPs to decontaminate dental unit waterlines, including their efficiency and toxicity. However, none of the studies reports the toxicity to neither animal cells 
Fig. 2 Risk of Bias for Included Studies

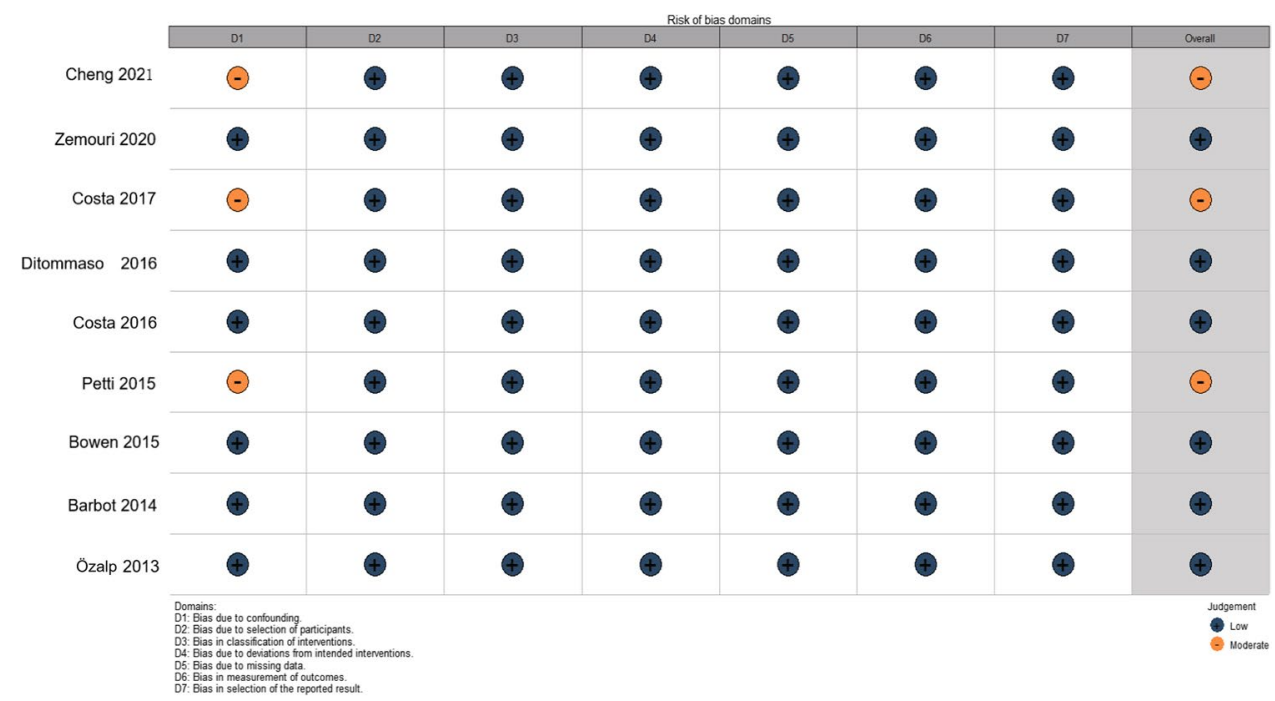

nor human beings, and most studies involve the antibacterial or anti-FLA ability of disinfectants. Overall, the results of these including studies show limited evidence that the use of silver or AgNPs has a potent effect on the decontamination of DUWLs.

\section{The Efficacy of Silver $(\mathbf{A g}+)$ Compounds Agent}

The application of silver in DUWLs is mainly synergistic with hydrogen peroxide $\left(\mathrm{H}_{2} \mathrm{O}_{2}\right)$ in the form of disinfectant currently. Using various common microorganisms in DUWLs or biofilms composed of these microorganisms as indicator organisms, the antibacterial efficacy of the disinfectant was demonstrated [33, 36, 37]. Hydrogen peroxide is a strong oxidant with weak acidity. It is active against a wide range of microorganisms, including bacteria propagules, yeasts, fungi, viruses, and spores [43]. In addition, it has a synergistic effect with many physical and chemical factors. Under the catalysis of ultraviolet rays or metal ions, it can accelerate the decomposition, producing various chemical groups, such as reactive oxygen species and free hydroxyl groups, which greatly enhance the killing effect on microorganisms [44]. A study on adding silver or copper to hydrogen peroxide for sewage disinfection treatment confirmed that both silver and copper can significantly improve the disinfection effect [45]. When $\mathrm{H}_{2} \mathrm{O}_{2}$ /silver contacting with microorganisms, silver acts as a catalyst to activate hydrogen peroxide. Silver once again acts as a stabilizer to protect the remaining hydrogen peroxide while cells are oxidized by the generated active oxides, which ensures the thoroughness and durability of sterilization. Furthermore, silver ions have been reported to also inhibit catalase enzyme which is produced by some bacteria and neutralize hydrogen peroxide [46]. The included study conducted by Barbot et al. [38] also proved that the survival rate of microorganisms was much more reduced in the case of treatment with $\mathrm{H}_{2} \mathrm{O}_{2}$ /silver than using $\mathrm{H}_{2} \mathrm{O}_{2}$ at a dose similar to that contained in $\mathrm{H}_{2} \mathrm{O}_{2} /$ silver. However, when compared with other commercial disinfectants, the disinfectant showed its disadvantages, namely low resistance to certain microorganisms, especially FLA in the DUWLs [3, 39].

$\mathrm{ICX}^{\odot}$ (contains silver nitrate) and $\mathrm{Citrisil}^{\odot}(0.00007 \%$ $\mathrm{Ag}$ ) had a different effect on heterotrophic bacteria and biofilm in dental unit water. Although they could significantly reduce the number of bacteria in output water comparing with the control group [40], their failure to control the biofilm in a simulated model was observed [41]. This may be related to the complex structure of biofilm and the low concentration of active ingredients in the disinfectants. There are symbiotic, reciprocal, and antagonistic relationships among bacteria within biofilms rather than plain accumulating of planktonic bacteria, giving the involved bacteria an impenetrable advantage [47].

\section{The Efficacy of Silver Nanoparticles (AgNPs)}

The rapid development of nanotechnology provides a potential means for designing novel and effective treatment options to control contamination of DUWLs. Compared with their bulk counterparts, silver nanomaterials display a larger surface area-to-volume ratio and higher reactivity, which equips them with the capability of exerting better antibacterial activity even at lower concentrations [48]. The ability of AgNPs to control oral biofilms involving specific oral pathogens since their high and broad-spectrum antimicrobial activity, as well as low drug resistance, has been demonstrated by extensive studies in dentistry [49]. Cheng et al. [35] compared the bacteriostatic effect of the liquid phase and solid phase AgNPs on DUWLs biofilms. It was demonstrated that solid phase AgNPs had a stronger antibacterial 
effect than liquid phase one, achieving no bacteria growth at different time points. The authors considered that the above result may be due to the decomposition or partial precipitation of active components in liquid phase AgNPs. To the best of our knowledge, however, there is no insufficient evidence to prove that solid phase AgNPs are indeed more antibacterial than liquid phase AgNPs. Studies have suggested that the activity of nanoparticles against bacteria is bound up with their properties, such as size, surface functionalization and charge, nanoparticle dose, particle coatings, steric factors, and colloidal stability [50]. We speculate that the unstabilized liquid phase AgNPs in suspension, which makes the particles easy to agglomerate, causing a decrease in surface area, lowering their surface of contact. Thereby, in above study it exhibits worse antibacterial efficiency than solid phase AgNPs that are finely dispersed in the physiological media [51]. More evidence and mechanism analysis of phase on the antibacterial properties of AgNPs still need further research.

The lifecycle of AgNPs has a crucial influence on the antimicrobial mode of action and efficiency. A study aimed to evaluate the potential physicochemical alterations of the AgNPs revealed its transformation in the DUWLs during the disinfection process [52]. The pristine AgNPs were primarily oxidated to $\mathrm{AgO}$ when being adsorbed onto biofilm surfaces to perform the antibacterial activity. Moreover, transformations to $\mathrm{AgCl}$ were observed after the disinfection process as tap water contains fairly high levels of chlorine, what can prove the ionization of silver from nanoparticles to silver ions. In addition, the polymeric stabilizing agent surrounding pristine AgNPs diminished over the disinfection process, leading to the aggregation of partial AgNPs. To make better use of the anti-biofilm properties of AgNPs, more in-depth researches to explore the mechanism of AgNPs on biofilms in DUWLs need to be conducted.

\section{The Efficacy of Silver Coating}

Besides being used as disinfectants, silver has been proposed as a component of coatings applied to the inner surface of waterline tubing to combat the formation of biofilm. Manufacturers are increasingly looking toward silver as the solution to controlling biofilms on DUWLs. Some of them have used this technology to produce DCU equipment coated with silver, such as those made by A-Dec ${ }^{\circledR}$. However, there is no adequate evidence to prove their efficacy in preventing the formation of biofilm in DUWLs. Unfortunately, the outcome of a study conducted by Lal et al. [42] was inconsistent with the expected result, which confirmed that a biofilm consisting of bacteria, fungi, and amoebae had formed on the lumen of dental waterline tubing with silver coating after 14 days. The authors did not explain the reason for the failure of silver against the biofilms in their study. The basic principle of silver-based coating engineering is to release silver ions from the coating over time to prevent the initial adhesion of bacteria and the subsequent formation of biofilms. The matrix in the coating encapsulates and releases silver particles, and the antibacterial agent itself determines the antibacterial ability [53]. Hence, we reckon the failure may be related to the insufficient dose of silver ions released in the coating. In addition, it may also be due to the complicated types of bacteria in DUWLs while silver is not sensitive to certain bacteria.

\section{Limitations of Silver or AgNPs Application in Dental Unit Water Treatment}

Silver has already been applied to DUWLs to control the contamination with microorganisms. However, extensive use may still encounter a series of challenges, particularly the sustainability and safety of silver and AgNPs. Consequently, the two most critical limitations involving technological and economic viability as well as the safety and toxicity of silver are discussed below.

\section{Technological and Economic Viability}

There are still a few obstacles hindering lab-scale AgNPsbased technologies being applied to the practical application despite their great antimicrobial property.

Firstly, the dispersion of AgNPs in the reaction system should be taken into account [53]. On the one hand, the application mode of suspending in the water, such as disinfection agents, can maintain their small particles state to increase the contact surface areas, accordingly improving the antimicrobial effect. But subsequent separation steps to achieve the recycling of nanoparticles simultaneously are needed [54]. Once being dispersed in the external environment, they are hard to retrieve and may become a potential source of a secondary pollutant [55]. On the other hand, the way of being fixed on the surface of the pipe would weaken the antimicrobial efficiency of AgNPs since that will affect the rate of silver ion release [56]. The selection of usage mode should depend on the specific application scenario and the target microorganism.

The second problem is that AgNPs may undergo agglomeration, reducing the antimicrobial ability or leading to the loss of antimicrobial activity [57]. Furthermore, because of the slenderness of DUWLs, AgNPs may deposit on the surface of the tubing and dead corners, resulting in blockage of waterlines. One promising means to address this issue is exerting robust immobilization strategies including anchoring and coating [58]. AgNPs can be immobilized on the surface of specific objects with suitable engineering technology, which enables a long-run effect [59]. 
Moreover, the synthesis process of AgNPs is complex, high cost, time-consuming, and it may involve many harmful chemicals [60]. The synthetic protocols for the production of AgNPs are of vital importance and they can be synthesized from a variety of methods including physical, chemical, and biological ways. The emergence of green synthesis opens an alternative way of alleviating the generation of harmful substances in the synthesis process [61]. But the technology is still immature currently, especially for large-scale production.

Compared with conventional methods, the cost of AgNPs-based disinfection technologies is higher commonly, due to the price of raw materials and the immaturity technology. Only when the cost and system of utilizing AgNPs are comparable to conventional methods will they have the opportunity to replace conventional disinfection approaches for the DUWLs.

\section{Safety and Toxicity}

Although silver has been currently used for medical purposes, there are still some controversies and ongoing debates regarding the cytotoxicity of human beings and other organisms. The toxicity of silver and AgNPs was suggested to be associated with the activity of silver ions released [62]. One of the most critical concerns in applications for the treatment of dental water is safety because silver ions released in the water have a chance to enter patients' oral cavities during clinical practice, causing unaware oral intake or impacting the micro-ecosystem of the oral cavity.

A recent review summarized the cytotoxic property of AgNPs by a series of in vitro and in vivo studies [63]. In vitro cell cultivation tests showed that AgNPs could be toxic to several human cell lines including human bronchial epithelial cells, red blood cells, human peripheral blood mononuclear cells, and liver cells. Additionally, AgNPs exhibited a concentration-, size- and time-dependent cytotoxicity, especially for those with sizes less than $10 \mathrm{~nm}$. An in vivo test revealed the ability of AgNPs to cross the blood-brain barrier (BBB) of mice through the circulation system, with eventual accumulation in the brain. Moreover, AgNPs tended to accumulate in other mice organs such as liver, spleen, and kidney, causing varying degrees of damages.

However, some studies have proved a different opinion. Munger et al. [64] conducted an in vivo study with two concentrations (10 ppm and $32 \mathrm{ppm}$ ) of commercial AgNPs solution over a 3-14 day-monitored human exposure. No clinically significant toxic effects were observed except that silver was detected in human serum. In the study of Zhu et al. [65], AgNPs immobilized on the surface of titanium implants by silver plasma immersion ion implantation (Ag-PIII) had no apparent toxic influence on the viability, proliferation, and differentiation of rat bone marrow mesenchymal stem cells. The authors suggested that using the proper Ag-PIII conditions could balance the antibacterial and osteogenic functions, which indicated safe and prolonged clinical applications.

The World Health Organization (WHO) recommends that silver with a concentration of $100 \mu \mathrm{g} / \mathrm{L}$ is tolerated without any risk to human health. Most studies involving silver ion release have shown that the leaching of silver ions in water is generally below the permissible limit value $[66,67]$.

\section{Strengths and Limitations of This Review}

The current review provides an update on the past literature, which mainly explores the application of silver to decontaminate dental unit waterlines, focusing on research over the past 10 years. Previous reviews involving DUWLs mostly described microbial contamination and discussed various treatment methods. This is the first systematic review discussing the application of silver in dental unit waterlines. However, there exist several limitations in this review. First and foremost, the limited relevant studies have resulted in a monotonous content of the included literature. There are no studies in the literature reporting silver-coated dental waterlines tubing in dental water treatment nor the toxicity of silver in the process of water treatment. Moreover, the follow-up time of including studies is not enough to evaluate long-term effects. In addition, due to the differences in the objects of research and methodology of each study, which substantially increase heterogeneity, meta-analysis is not available.

\section{Future Research}

Additional studies are needed for understanding the application of silver and AgNPs to decontaminate DUWLs. Future studies that assess the efficiency of silver need to use standardized outcome evaluation criteria, such as killing rate or log load reduction. Moreover, further research could evaluate the antimicrobial efficacy of silver in new applications, e.g., coating to the luminal surface or combine with filters. Additionally, longer follow-up studies are needed to determine the duration of effect over time. In regard to AgNPs, more in-depth researches to explore the anti-biofilm mechanism in DUWLs need to be conducted to make better use of their anti-biofilm properties. Comparing the anti-biofilm efficacy of AgNPs with other disinfectants for disinfection in DUWLs is also a research direction with application value. Researchers also need to pay close attention to the safety of commercial silver-based products at different concentrations in the future. 


\section{Conclusions}

The current review on the application of silver to decontaminate dental unit water has identified the following conclusions:

1. The studies in the current analysis showed good evidence of microbicidal efficacy of silver synergistic with hydrogen peroxide on selective microbes in DUWLs. Moreover, there is an evidence to show that continuous treatment with $\mathrm{H}_{2} \mathrm{O}_{2}$ /silver is possibly an effective way against biofilm attached to the inner surfaces of the DUWLs. When compared with other commercial disinfectants, however, $\mathrm{H}_{2} \mathrm{O}_{2}$ /silver displayed unsatisfactory anti-FLA activities.

2. Commercial disinfectant tablets containing silver, such as ICX ${ }^{\odot}$ and Citrisil $^{\odot}$, had antimicrobial efficacy on heterotrophic bacteria in dental unit water, but they failed to control the biofilm derived from dental water bacteria.

3. There is insufficient evidence in the application of AgNP as an effective disinfectant in dental clinics.

4. There is no evidence to prove the efficacy of silver coating in preventing the formation of biofilm in DUWLs.

In summary, this current review aims to present the application of silver/AgNPs and discuss the remaining advantage and limitations. Considering the unchecked spread of the pandemic of COVID-19 and the unique nature of dental practice, strategies must be developed to minimize the risk of cross-infection rising from dental unit water. There are sparse post-treatment data of either the bactericidal and bacteriostatic effects of silver or AgNPs, especially the actual clinical efficacy of long-term application. To better evaluate the clinical application of silver-based compounds or AgNPs as disinfectants in DUWLs, there is a need to generate the high level of evidence by standardizing the methods of experimental protocols and outcome assessment criteria. Moreover, in-depth investigations concerning the amount of silver ion released must be conducted due to the safety issue. More high-quality research is needed to resolve the gap in our knowledge on the optimal dosage and treatment options required to control bacterial and biofilm in DUWLs with silver-containing materials.

Author Contribution FH, PC, and XY contributed to the study conception and design. Material preparation, data collection, and analysis were performed by $\mathrm{FH}$ and PC. The first draft of the manuscript was written by FH. QC contributed to the revision of the manuscript. All authors read and approved the final manuscript.

Funding This work was supported by Zhejiang Province Public Welfare Technology Application Research Project (Grant number [LGF21H190003]).

\section{Declarations}

Competing Interests The authors declare no competing interests.

\section{References}

1. Coleman DC, O’Donnell MJ, Shore AC, Swan J, Russell RJ (2007) The role of manufacturers in reducing biofilms in dental chair waterlines. J Dent 35:701-711. https://doi.org/10.1016/j. jdent.2007.05.003

2. O'Donnell MJ, Boyle MA, Russell RJ, Coleman DC (2011) Management of dental unit waterline biofilms in the 21st century. Future Microbiol 6:1209-1226. https://doi.org/10.2217/fmb.11. 104

3. Costa D, Girardot M, Bertaux J, Verdon J, Imbert C (2016) Efficacy of dental unit waterlines disinfectants on a polymicrobial biofilm. Water Res 91:38-44. https://doi.org/10.1016/j.watres. 2015.12.053

4. Vestby LK, Grønseth T, Simm R, Nesse LL (2020) Bacterial biofilm and its role in the pathogenesis of disease. Antibiotics 9:59. https://doi.org/10.3390/antibiotics9020059

5. Hernández-Jim-nez E, Del Campo R, Toledano V, Vallejo-Cremades MT, Muñoz A, Largo C, Arnalich F, GarcíarcGarc FCubillos-Zapata C, LZpez-Collazo E, (2013) Biofilm vs. planktonic bacterial mode of growth: which do human macrophages prefer? Biochem Bioph Res Co 441:947-952. https://doi.org/10.1016/j.bbrc.2013.11.012

6. Barbeau J, Tanguay R, Faucher E, Avezard C, Trudel L, Côtéôt CPrévost AP (1996) Multiparametric analysis of waterline contamination in dental units. Appl Environ Microb 62:3954-3959. https://doi.org/10.1128/aem.62.11.3954-3959.1996

7. Kohn WG, Collins AS, Cleveland JL, Harte JA, Eklund KJ, Malvitz DM (2003) Guidelines for infection control in dental health-care settings-2003. MMWR Recomm Rep 52(RR-17):1-61

8. Walker JT, Marsh PD (2007) Microbial biofilm formation in DUWS and their control using disinfectants. J Dent 35:721-730. https://doi.org/10.1016/j.jdent.2007.07.005

9. Volgenant CMC, Persoon IF (2019) Microbial water quality management of dental unit water lines at a dental school. J Hosp Infect 103:e115-e117. https://doi.org/10.1016/j.jhin.2018.11.002

10. Bjarnsholt $\mathrm{T}$ (2013) The role of bacterial biofilms in chronic infections. APMIS 121:1-58. https://doi.org/10.1111/apm.12099

11. Ho S, Lue K, Ku M (2019) Allergic rhinitis, rather than asthma, might be associated with dental caries, periodontitis, and other oral diseases in adults. PeerJ 7:e7643. https://doi.org/10.7717/ peerj. 7643

12. Polednik B (2021) Exposure of staff to aerosols and bioaerosols in a dental office. Build Environ 187:107388. https://doi.org/10. 1016/j.buildenv.2020.107388

13. Ricci ML, Fontana S, Pinci F, Fiumana E, Pedna MF, Farolfi P, Sabattini MA, Scaturro M (2012) Pneumonia associated with a dental unit waterline. Lancet 379:684. https://doi.org/10.1016/ S0140-6736(12)60074-9

14. Zhou Y, Kong Y, Kundu S, Cirillo JD, Liang H (2012) Antibacterial activities of gold and silver nanoparticles against Escherichia coli and bacillus Calmette-Guérin. J Nanobiotechnol 10:19. https://doi.org/10.1186/1477-3155-10-19

15. Wang L, Zhang S, Keatch R, Corner G, Nabi G, Murdoch S, Davidson F, Zhao Q (2019) In-vitro antibacterial and anti-encrustation performance of silver-polytetrafluoroethylene nanocomposite coated urinary catheters. J Hosp Infect 103:55-63. https://doi. org/10.1016/j.jhin.2019.02.012 
16. Marin S, Vlasceanu GM, Tiplea RE, Bucur IR, Lemnaru M, Marin MM, Grumezescu AM (2015) Applications and toxicity of silver nanoparticles: a recent review. Curr Top Med Chem 15:15961604. https://doi.org/10.2174/1568026615666150414142209

17. Galdiero S, Falanga A, Vitiello M, Cantisani M, Marra V, Galdiero M (2011) Silver nanoparticles as potential antiviral agents. Molecules 16:8894-8918. https://doi.org/10.3390/molecules161088 94

18. Jeremiah SS, Miyakawa K, Morita T, Yamaoka Y, Ryo A (2020) Potent antiviral effect of silver nanoparticles on SARS-CoV-2. Biochem Bioph Res Co 533:195-200. https://doi.org/10.1016/j. bbrc.2020.09.018

19. Silvestry-Rodriguez N, Sicairos-Ruelas EE, Gerba CP, Bright KR (2007) Silver as a disinfectant. Rev Environ Contam Toxicol 191:23-45. https://doi.org/10.1007/978-0-387-69163-3_2

20. Khan ST, Malik A, Wahab R, Abd-Elkader OH, Ahamed M, Ahmad J, Musarrat J, Siddiqui MA, Al-Khedhairy AA (2017) Synthesis and characterization of some abundant nanoparticles, their antimicrobial and enzyme inhibition activity. Acta Microbiol Immunol Hung 64:203-216. https://doi.org/10.1556/030.64.2017. 004

21. Ivask A, Kurvet I, Kasemets K, Blinova I, Aruoja V, Suppi S, Vija H, Käkinen A, Titma T, Heinlaan M, Visnapuu M, Koller D, Kisand V, Kahru A (2014) Size-dependent toxicity of silver nanoparticles to bacteria, yeast, algae, crustaceans and mammalian cells in vitro. PLoS ONE 9:e102108. https://doi.org/10.1371/ journal.pone. 0102108

22. Durán N, Durán M, de Jesus MB, Seabra AB, Fávaro WJ, Nakazato G (2016) Silver nanoparticles: a new view on mechanistic aspects on antimicrobial activity. Nanomedicine 12:789-799. https://doi.org/10.1016/j.nano.2015.11.016

23. Zhang Y, Wan Y, Shi Y, Pan G, Yan H, Xu J, Guo M, Qin L, Liu $Y$ (2016) Facile modification of thin-film composite nanofiltration membrane with silver nanoparticles for anti-biofouling. J Polym Res 23:105. https://doi.org/10.1007/s10965-016-0992-7

24. Yin IX, Zhang J, Zhao IS, Mei ML, Li Q, Chu CH (2020) The antibacterial mechanism of silver nanoparticles and its application in dentistry. Int J Nanomedicine 15:2555-2562. https://doi.org/10. 2147/IJN.S246764

25. Jiang Q, Chen J, Yang C, Yin Y, Yao K (2019) Quorum sensing: a prospective therapeutic target for bacterial diseases. Biomed Res Int 2019:2015978. https://doi.org/10.1155/2019/2015978

26. Auger S, Krin E, Aymerich S, Gohar M (2006) Autoinducer 2 affects biofilm formation by Bacillus cereus. Appl Environ Microb 72:937-941. https://doi.org/10.1128/AEM.72.1.937-941.2006

27. Liaqat I, Bachmann RT, Sabri AN, Edyvean RGJ (2010) Isolate-specific effects of patulin, penicillic acid and EDTA on biofilm formation and growth of dental unit water line biofilm isolates. Curr Microbiol 61:148-156. https://doi.org/10.1007/ s00284-010-9591-8

28. LaSarre B, Federle MJ (2013) Exploiting quorum sensing to confuse bacterial pathogens. Microbiol Mol Biol Rev 77:73-111. https://doi.org/10.1128/MMBR.00046-12

29. Ilk S, Tan G, Emül E, Sağlam N (2020) Investigation the potential use of silver nanoparticles synthesized by propolis extract as $\mathrm{N}$-acyl-homoserine lactone-mediated quorum sensing systems inhibitor. Turk J Med Sci 50:1147-1156. https://doi.org/10.3906/ sag-2004-148

30. Singh BR, Singh BN, Singh A, Khan W, Naqvi AH, Singh HB (2015) Mycofabricated biosilver nanoparticles interrupt Pseudomonas aeruginosa quorum sensing systems. Sci Rep-Uk 5:13719. https://doi.org/10.1038/srep13719

31. Hayat S, Muzammil S, Shabana AB, Siddique MH, Saqalein M, Nisar MA (2019) Quorum quenching: role of nanoparticles as signal jammers in Gram-negative bacteria. Future Microbiol 14:61-72. https://doi.org/10.2217/fmb-2018-0257
32. Dallolio L, Scuderi A, Rini MS, Valente S, Farruggia P, Sabattini MA, Pasquinelli G, Acacci A, Roncarati G, Leoni E (2014) Effect of different disinfection protocols on microbial and biofilm contamination of dental unit waterlines in community dental practices. Int J Environ Res Public Health 11:2064-2076. https://doi.org/10. 3390/ijerph110202064

33. Ditommaso S, Giacomuzzi M, Ricciardi E, Zotti CM (2016) Efficacy of a low dose of hydrogen peroxide (peroxy Ag+) for continuous treatment of dental unit water lines: challenge test with Legionella pneumophila Serogroup 1 in a simulated dental unit waterline. Int J Environ Res Public Health 13:745. https://doi.org/ 10.3390/ijerph13070745

34. Sterne JA, HernáernA, Reeves BC, SavovićavovBerkman ND, Viswanathan M, Henry D, Altman DG, Ansari MT, Boutron I, Carpenter JR, Chan A, Churchill R, Deeks JJ, Hróbjartsson A, Kirkham J, Jkni P, Loke YK, Pigott TD, Ramsay CR, Regidor D, Rothstein HR, Sandhu L, Santaguida PL, Schünemann HJ, Shea B, Shrier I, Tugwell P, Turner L, Valentine JC, Waddington H, Waters E, Wells GA, Whiting PF, Higgins JP (2016) ROBINSI: a tool for assessing risk of bias in non-randomised studies of interventions. BMJ:i4919. https://doi.org/10.1136/bmj.i4919

35. Cheng L, Naibijiang N, Hasenbai A, Dong H, He H (2021) Bacteriostatic effects of nanometer silver disinfectant on the biofilms in dental unit water lines. J Dent Sci 16:327-332. https://doi.org/ 10.1016/j.jds.2020.03.015

36. Özalp M, Bulut ÖE, Ataç AS, Ekizoğlu M, Kart D, Çelik HH, Tatar I (2013) The effect of hydrogen peroxide/colloidal silver on reducing the colonization and growth of heterotrophic bacteria in dental unit waterlines. Turk J Biol 37:336-341. https://doi.org/10. 3906/biy-1204-23

37. Petti S, Polimeni A, Allen MJ (2015) Dental unit water treatment with hydrogen peroxide and monovalent silver ions artificially contaminated with freshly isolated pathogens. Ann Ig 27:789798. https://doi.org/10.7416/ai.2015.2072

38. Barbot V, Costa D, Deborde M, Imbert C (2014) Efficacy of dental unit disinfectants against Candida spp. and Hartmannella vermiformis. Pathog Dis 70:289-296. https://doi.org/10.1111/2049$632 X .12127$

39. Costa D, Bossard V, Brunet K, Fradin B, Imbert C (2017) Planktonic free-living amoebae susceptibility to dental unit waterlines disinfectants. Pathog Dis 75. https://doi.org/10.1093/femspd/ ftx099

40. Bowen CG, Greenwood W, Guevara P, Washington MA (2015) Effectiveness of a dental unit waterline treatment protocol with A-Dec ICX and Citrisil disinfectants. Mil Med 180:1098-1104. https://doi.org/10.7205/MILMED-D-14-00643

41. Zemouri C, de Soet JJ, Volgenant C, Crielaard W, Laheij A (2020) Heterogeneity in the efficacy of dental chemical disinfectants on water-derived biofilms in vitro. Biofouling 36:587-596. https:// doi.org/10.1080/08927014.2020.1782894

42. Lal S, Pearce M, Achilles-Day UE, Day JG, Morton LH, Crean SJ, Singhrao SK (2017) Developing an ecologically relevant heterogeneous biofilm model for dental-unit waterlines. Biofouling 33:75-87. https://doi.org/10.1080/08927014.2016.1260710

43. Block SS (2001) Peroxygen compounds. In: Block SS (ed) Disinfection, sterilization, and preservation. Lippincott Williams \& Wilkins, Philadelphia, pp 185-204

44. Song W, Cheng M, Ma J, Ma W, Chen C, Zhao J (2006) Decomposition of hydrogen peroxide driven by photochemical cycling of iron species in clay. Environ Sci Technol 40:4782-4787. https:// doi.org/10.1021/es060624q

45. Orta DVM, YMñez-Noguez I, Jimunez-Cisneros B, Luna PV, (2008) Adding silver and copper to hydrogen peroxide and peracetic acid in the disinfection of an advanced primary treatment effluent. Environ Technol 29:1209-1217. https://doi.org/10.1080/ 09593330802270632 
46. Alkawareek MY, Bahlool A, Abulateefeh SR, Alkilany AM (2019) Synergistic antibacterial activity of silver nanoparticles and hydrogen peroxide. PLoS ONE 14:e220575. https://doi.org/10.1371/ journal.pone.0220575

47. Inui T, Walker LC, Dodds MWJ, Hanley AB (2015) Extracellular glycoside hydrolase activities in the human oral cavity. Appl Environ Microb 81:5471-5476. https://doi.org/10.1128/AEM. 01180-15

48. Yao B, Zhang J, Fan X, He J, Li Y (2019) Surface engineering of nanomaterials for photo-electrochemical water splitting. Small 15:1803746. https://doi.org/10.1002/smll.201803746

49. Noronha VT, Paula AJ, Durán G, Galembeck A, Cogo-Müller K, Franz-Montan M, Durán N (2017) Silver nanoparticles in dentistry. Dent Mater 33:1110-1126. https://doi.org/10.1016/j.dental. 2017.07.002

50. Joo SH, Aggarwal S (2018) Factors impacting the interactions of engineered nanoparticles with bacterial cells and biofilms: mechanistic insights and state of knowledge. J Environ Manage 225:62-74. https://doi.org/10.1016/j.jenvman.2018.07.084

51. Anees Ahmad S, Sachi Das S, Khatoon A, Tahir Ansari M, Afzal M, Saquib Hasnain M, Kumar Nayak A (2020) Bactericidal activity of silver nanoparticles: a mechanistic review. Materials Science for Energy Technologies 3:756-769. https://doi.org/10.1016/j. mset.2020.09.002

52. Gitipour A, Al-Abed SR, Thiel SW, Scheckel KG, Tolaymat T (2017) Nanosilver as a disinfectant in dental unit waterlines: assessment of the physicochemical transformations of the AgNPs. Chemosphere 173:245-252. https://doi.org/10.1016/j.chemo sphere.2017.01.050

53. Li Q, Mahendra S, Lyon DY, Brunet L, Liga MV, Li D, Alvarez PJJ (2008) Antimicrobial nanomaterials for water disinfection and microbial control: potential applications and implications. Water Res 42:4591-4602. https://doi.org/10.1016/j.watres.2008.08.015

54. Tugulea AM, Bérubé D, Giddings M, Lemieux F, Hnatiw J, Priem J, Avramescu ML (2014) Nano-silver in drinking water and drinking water sources: stability and influences on disinfection by-product formation. Environ Sci Pollut R 21:11823-11831. https://doi. org/10.1007/s11356-014-2508-5

55. Lowry GV, Gregory KB, Apte SC, Lead JR (2012) Transformations of nanomaterials in the environment. Environ Sci Technol 46:6893-6899. https://doi.org/10.1021/es300839e

56. Ahamed M, AlSalhi MS, Siddiqui MKJ (2010) Silver nanoparticle applications and human health. Clin Chim Acta 411:1841-1848. https://doi.org/10.1016/j.cca.2010.08.016

57. Reda M, Ashames A, Edis Z, Bloukh S, Bhandare R, Abu Sara H (2019) Green synthesis of potent antimicrobial silver nanoparticles using different plant extracts and their mixtures. Processes 7:510. https://doi.org/10.3390/pr7080510
58. Huo Z, Du Y, Chen Z, Wu Y, Hu H (2020) Evaluation and prospects of nanomaterial-enabled innovative processes and devices for water disinfection: a state-of-the-art review. Water Res 173:115581. https://doi.org/10.1016/j.watres.2020.115581

59. Rahaman MS, Vecitis CD, Elimelech M (2012) Electrochemical carbon-nanotube filter performance toward virus removal and inactivation in the presence of natural organic matter. Environ Sci Technol 46:1556-1564. https://doi.org/10.1021/es203607d

60. Buttacavoli M, Albanese NN, Di Cara G, Alduina R, Faleri C, Gallo M, Pizzolanti G, Gallo G, Feo S, Baldi F, Cancemi P (2018) Anticancer activity of biogenerated silver nanoparticles: an integrated proteomic investigation. Oncotarget 9:9685-9705. https:// doi.org/10.18632/oncotarget.23859

61. Khandel P, Yadaw RK, Soni DK, Kanwar L, Shahi SK (2018) Biogenesis of metal nanoparticles and their pharmacological applications: present status and application prospects. J Nanostructure Chem 8:217-254. https://doi.org/10.1007/s40097-018-0267-4

62. García-Contreras R, Argueta-Figueroa L, Mejía-Rubalcava C, Jiménez-Martínez R, Cuevas-Guajardo S, Sánchez-Reyna PA, Mendieta-Zeron H (2011) Perspectives for the use of silver nanoparticles in dental practice. Int Dent J 61:297-301. https://doi.org/ 10.1111/j.1875-595X.2011.00072.x

63. Liao C, Li Y, Tjong S (2019) Bactericidal and cytotoxic properties of silver nanoparticles. Int J Mol Sci 20:449. https://doi.org/10. 3390/ijms20020449

64. Munger MA, Radwanski P, Hadlock GC, Stoddard G, Shaaban A, Falconer J, Grainger DW, Deering-Rice CE (2014) In vivo human time-exposure study of orally dosed commercial silver nanoparticles. Nanomedicine-Uk 10:1-9. https://doi.org/10.1016/j.nano. 2013.06.010

65. Zhu Y, Cao H, Qiao S, Wang M, Gu Y, Luo H, Meng F, Liu X, Lai H (2015) Hierarchical micro/nanostructured titanium with balanced actions to bacterial and mammalian cells for dental implants. Int J Nanomedicine 10:6659-6674. https://doi.org/10. 2147/IJN.S92110

66. Chen W, Jiang J, Zhang W, Wang T, Zhou J, Huang CH, Xie X (2019) Silver nanowire-modified filter with controllable silver ion release for point-of-use disinfection. Environ Sci Technol 53:7504-7512. https://doi.org/10.1021/acs.est.9b01678

67. Tyagi N, Thangadurai P, Suresh S (2020) Application of bacterial cellulose-silver nanoprism composite for detoxification of endosulfan and inactivation of Escherichia coli cells. Int J Environ Sci Te 17:1713-1726. https://doi.org/10.1007/s13762-019-02510-4

Publisher's Note Springer Nature remains neutral with regard to jurisdictional claims in published maps and institutional affiliations. 